\title{
Vida e poder - reflexões acerca da pandemia atual
}

\author{
Life and power - considerations on the current pandemic
}

\section{Davi Maranhão De Conti*}

\begin{abstract}
Resumo: Este artigo se divide em quatro partes. Inicialmente apresentamos a noção de biopolítica de modo introdutório, considerando a relação entre poder soberano e biopoder. Voltamo-nos para a elaboração foucaultiana do termo de modo a esclarecer, em linhas gerais, seu sentido. Essa breve análise da noção de biopolítica encaminha-nos para o conceito de tanatopolítica, que aparece, na segunda parte do texto, como epíteto da derivação funesta da biopolítica. Na terceira parte, a partir de uma perspectiva biopolítica, lançamos luz sobre a crise que enfrentamos. Trata-se de um esforço de evidenciar o sentido biopolítico da crise atual, considerando o conteúdo das reflexões de Foucault. Finalmente, na quarta parte, atualizamos o debate acerca da biopolítica por meio de uma análise da noção de imunidade formulada por Esposito, a qual fornece uma importante chave interpretativa da pandemia atual.
\end{abstract}

Palavras-chave: Biopolítica; Anatomopolítica; Soberania; Imunidade; Pandemia

Abstract: This article is divided into four parts. In the first part, we briefly introduce the concept of biopolitics, considering above all the relationship between sovereign power and biopower. We then turn to Foucault's elaboration of the concept in order to clarify meaning in general lines. This brief analysis of the notion of biopolitics leads us to the idea of thanatopolitics, which emerges, in the second part of the text, as the epithet of the mortal derivation of biopolitics. In the third part, from a biopolitical perspective, we shed light on the crisis we face. It is an effort to highlight the biopolitical meaning of the current crisis, considering the content of Foucault's reflections. Finally, in the fourth part, we update the debate about biopolitics through an analysis of the notion of immunity formulated by Esposito, which provides an important interpretive key of the current pandemic.

Keywords: Biopolitics; Anatomopolitics; Sovereignty; Immunity; Pandemic

A pandemia atual alça a noção de biopolítica ao centro da reflexão político-filosófica. 0 conceito, que ganha força sobretudo após a publicação dos cursos realizados por Foucault no Collège de France entre meados da década de 1970 e início da década de 1980, entra definitivamente para o debate acerca da política contemporânea. Essa entrada é garantida, por um lado, pela intensificação dos mecanismos de controle - que se materializa no uso de pistolas de medição de temperatura em locais públicos, na intensificação do rastreamento via celular, bem como na contínua triagem da população de risco -, e, por outro lado, pelo uso cada vez mais frequente do termo por aqueles que se dispõem a pensar a política, entre eles, Giorgio Agamben, Antonio Negri, Michael Hardt e Roberto Esposito, cujas hipóteses, em alguma medida, consideraremos neste texto.

Este artigo se divide em quatro partes: na primeira apresentamos brevemente o conceito de biopolítica; na segunda consideramos de modo introdutório a derivação tanatopolítica desse conceito; na terceira lançamos luz sobre a pandemia atual a partir de uma perspectiva biopolítica; na quarta expomos as contribuições de Roberto Esposito para a compreensão do conceito de biopolítica, bem como para a análise da crise que nos assola. Trata-se de um esforço de relacionar a crise atual à biopolítica, considerando não apenas o conteúdo das reflexões de Foucault, mas também a atualização de seu pensamento realizada

* Mestre em Filosofia pelo Programa de Pós-graduação em Filosofia da Universidade Federal de Goiás, Goiânia, GO. E-mail: decontidavi@gmail.com ORCID: https://orcid.org/0000-0003-4351-7053 
por Roberto Esposito. Como veremos, o conceito de imunidade em Esposito oferece uma importante chave de leitura da problemática biopolítica. Nosso objetivo é, acima de tudo, definir linhas mestras a partir das quais se possa aprofundar análises acerca da pandemia.

O conceito de biopolítica, como se sabe, não é um neologismo foucaultiano e surge muito antes de seu uso pelo filósofo francês. A história desse termo abordo de modo introdutório no artigo intitulado "Biopolíticas - itinerário de um conceito", que será publicado em breve ${ }^{1}$. Relevante para delimitar o campo semântico da noção de biopolítica, a história do termo não faz falta aqui porque a interpretação de Foucault marca uma ruptura em relação às leituras que a precedem. Ele não utiliza conceitos biológicos para fundamentar a ação política, o que se leva a cabo no organicismo de princípios do século XX, e nem considera os processos da vida como objeto da política, o que se realiza nos estudos bioéticos ${ }^{2}$. Em vez disso, Foucault lança luz sobre o modo como a vida se torna o elemento central das estratégias de poder.

Foucault utiliza o conceito de biopolítica em apenas uma das obras que receberam seu imprimatur. 0 primeiro volume de História da Sexualidade é o único de seus livros publicados em vida em que aborda explicitamente o termo. No último capítulo dessa obra, intitulado "Direito de morte e poder sobre a vida", Foucault define o biopoder em oposição ao poder soberano. Estabelece-se uma relação bastante elusiva entre essas duas racionalidades de poder. Sob determinado ângulo, as duas noções revelam-se nitidamente distintas. Como nota Esposito, os trechos em que Foucault faz prevalecer uma descontinuidade entre as duas formas de poder são à primeira vista unívocos: "não apenas a biopolítica difere da soberania, mas há entre ambas uma cesura nítida e irreversível"3.

Essa diferença entre poder soberano e biopoder pode ser sintetizada na famosa formulação de Foucault segundo a qual "o velho direito de causar a morte ou deixar viver foi substituído por um poder de causar a vida ou devolver à morte" 4 . 0 poder de morte que caracteriza a soberania é deslocado por um poder que se volta para a vida e seu contínuo incremento. A diferença não poderia ser mais evidente: ao passo que, no regime soberano, a vida é apenas aquilo que escapa ao poder de fazer morrer, no biopoder, a vida torna-se o elemento central, e a morte apenas a fronteira necessária.

A morte deixa de ser o signo do poder, e a vida toma o seu lugar: "a velha potência de morte em que se simbolizava o poder soberano é agora, cuidadosamente, recoberta pela

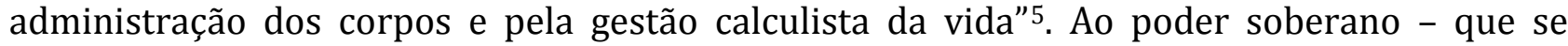
exercia como "instância de confisco, mecanismo de subtração, direito de se apropriar de uma parte das riquezas" ${ }^{-}$, sobrepõe-se uma forma de poder que se destina a "produzir forças, a fazê-las crescer e a ordená-las mais do que a barrá-las, dobrá-las ou destruí-las"7.

Essa alteração na racionalidade de poder se relaciona às diversas transformações que ocorreram entre os séculos XVII e XVIII. Ao avanço das disciplinas em instituições como exército, escola e hospital, ao desenvolvimento de técnicas de adestramento do corpo, que visam ao "crescimento paralelo de sua utilidade e docilidade" 8 , somam-se, um pouco mais tarde, as regulações da população. A expansão demográfica do século XVIII, o aumento da produção industrial e agrícola, o avanço da estatística, assim como o crescente conhecimento médico e científico acerca do corpo humano, foram fundamentais para o desenvolvimento do biopoder.

\footnotetext{
1 https://enpgfilunb.wixsite.com/home/colecao-cadernos

2 LEMKE, Biopolitics: an advanced introduction, 4.

${ }^{3}$ ESPOSITO, Bios: Biopolítica e filosofia, 45.

${ }^{4}$ FOUCAULT, História da sexualidade: a vontade de saber, 149.

${ }^{5}$ FOUCAULT, História da sexualidade: a vontade de saber, 150.

${ }^{6}$ FOUCAULT, História da sexualidade: a vontade de saber, 146.

${ }^{7}$ FOUCAULT, História da sexualidade: a vontade de saber, 146.

${ }^{8}$ FOUCAULT, História da sexualidade: a vontade de saber, 150.
} 
O biopoder, como explica Foucault, é um poder bipolar: o primeiro polo (anatomopolítica) desenvolve-se por volta do século XVII e se dirige para o indivíduo; o segundo (biopolítica) ganha vulto posteriormente, no século XVIII, e volta-se não para o indivíduo, mas para a população. 0 primeiro "centrou-se no corpo como máquina: no seu adestramento, na ampliação de suas aptidões, na extorsão de suas forças"; o segundo, "no corpo-espécie, no corpo transpassado pela mecânica do ser vivo e como suporte dos processos biológicos"9. 0 surgimento da figura da população está na origem da biopolítica, modalidade de poder cujo fundamento liberal se faz evidente no tratamento da população como dado natural, sobre o qual se deveria intervir apenas para garantir a dinâmica do capital.

Como já mencionamos, Foucault estabelece uma relação imprecisa entre poder soberano e biopoder. A descontinuidade entre essas racionalidades de poder, que se evidencia com bastante nitidez ao primeiro olhar, obscurece-se à sombra da morte, mais precisamente, do poder de morte. A nova racionalidade de poder (anatomo e biopolítica) não apenas conserva o poder de morte que define a soberania, como também, paradoxalmente, emprestalhe um caráter hiperbólico. É natural, portanto, questionar como é possível que no ponto culminante da política da vida se tenha gerado uma potência mortífera levada a contradizer seu impulso produtivo. Para Foucault, é o racismo que permite introduzir, no interior do biopoder, uma cisão entre o que deve viver e o que deve morrer.

A hierarquia que se estabelece entre seres humanos superiores e inferiores, normais e anormais garante a continuidade do poder de morte no interior da mecânica do biopoder. Um poder que se volta para a vida, para seu contínuo aprimoramento, pode alcançar desdobramentos macabros, percebendo na morte do outro, do anormal, um modo de melhorar a vida. Essa dinâmica permite redirecionar o poder de morte não apenas ao outro, mas a si próprio e a cada um. É o que ocorre no Nacional-Socialismo alemão. Como observa Foucault, "não é simplesmente a destruição das outras raças o objetivo do regime nazista. A destruição das outras raças é uma das faces do projeto, sendo a outra face expor sua própria raça ao perigo absoluto e universal da morte" 10 .

Ainda que se possa considerar o nazismo como estratégia biopolítica par excellence, porque eleva o controle sobre vida à sua dimensão genética, não se deve tomá-lo como forma cristalizada do biopoder, mas antes como sua derivação tanatopolítica. A morte do outro ganha um sinal positivo: matar significa tornar-se mais puro. A morte da "raça inferior" tornase um meio para melhorar a vida em geral, que o outro morra significa que eu vivo mais. Isso permite direcionar o poder de morte não somente ao outro, à "raça inferior", mas à sociedade como um todo.

A continuidade do poder de morte no interior do biopoder pode ser considerada ou como resquício do poder soberano ou como resultado da própria dinâmica de um poder que se volta para o incremento da vida. Essa dualidade constitutiva do conceito de biopolítica resulta tanto de sua elaboração por Foucault quanto do próprio termo, que reúne vida (bios) e política em uma relação de exterioridade interna, marcada pela ambiguidade entre uma leitura que realça a ideia de um poder da vida e outra que reforça a hipótese de um poder sobre a vida. Como observa Maria Muhle: "ao passo que a primeira interpretação premia a vida com um poder intrínseco que resiste ao biopoder, como propõem Antonio Negri e Michael Hardt, a última, proposta por Giorgio Agamben, radicaliza o aspecto tanatopolítico na noção de 'vida nua'"11.

Para Muhle, esses autores se sentem tentados a definir a noção de vida por acreditarem que a indefinição desse conceito revela uma carência no pensamento de Foucault. Ignoram

\footnotetext{
${ }^{9}$ FOUCAULT, História da sexualidade: a vontade de saber, 150.

10 FOUCAULT, Em defesa da sociedade, 310.

11 MUHLE, A genealogyof biopolitics: the notion of life in Canguilhem and Foucault. In: The Government of Life: Foucault, Biopolitics and Neoliberalism, 77, tradução nossa.
} 
assim que é uma opção metodológica que deve ser levada a sério. A precisão das reflexões de Foucault acerca da biopolítica devem-se precisamente a essa indeterminação, que pode ser entendida como "normalização" da vida por estratégias de poder-saber. Como explica Muhle,

a ausência de uma definição da vida no pensamento de Foucault não é nem um lapso nem uma inexatidão, mas uma indeterminação intencional, que se opõe, por um lado, a uma interpretação da vida como força que a situa para além dos mecanismos de poder e, por outro, a uma reformulação ontológica dessa mesma indeterminação que considera a vida em sua nudez radical ${ }^{12}$.

A noção de vida em Foucault é destituída de qualquer estatuto ontológico. A vida é um correlato de técnicas e estratégias de poder e de saber. De acordo com Muhle, apenas se tomarmos essa indeterminação da noção de vida no pensamento de Foucault com a devida seriedade é que nos habilitaremos a compreender o modus operandi de um poder que imita a dinâmica da vida. A vida deve ser entendida, segundo a autora, em um duplo sentido, como objeto das técnicas de poder e, em sua dimensão dinâmica, como seu modelo operacional. Não é possível falar de um poder da vida que impõe ou excede o poder sobre a vida, um vez que para "governar a vida, as formas de biopoder imitam ou mimetizam a própria dinâmica da vida, quer dizer, sua polaridade entre vida e morte, ou entre autotransgressão e autoconservação, entre o normal [...] e o patológico"13.

Se Muhle reconhece na indeterminação do conceito de vida a chave interpretativa capaz de livrar o a noção de biopolítica da oscilação entre uma leitura negativa e uma positiva, Esposito reconhece-a na noção de imunidade. 0 vácuo entre uma versão negativa e uma versão eufórica do biopoder pode ser preenchido pelo conceito de imunidade porque ele permite compreender como é possível que um poder que se volta para o incremento da vida se revele também como poder de morte.

Ao estabelecer o caráter dual da imunização como proteção e negação da vida, Esposito cria um elo que dissipa a ambiguidade no interior do biopoder. Para Esposito ${ }^{14}$, o poder de morte que caracteriza a face negativa do biopoder não é exercido de fora como um violento poder de subjugação, é antes um efeito da maneira contraditória em que a vida busca por si própria defender-se das ameaças que a constrangem. Como observa Esposito ${ }^{15}$, a imunidade é necessária à manutenção da vida, mas, se assume uma forma que exclui qualquer alteridade, acaba por arrestar seu próprio desenvolvimento.

Passemos a uma análise inicial da pandemia sob uma ótica biopolítica antes de considerarmos a contribuição de Esposito para essa análise. Lembremo-nos que Foucault, em Vigiar e Punir - considerando um regulamento de final do século XVII acerca das medidas que se deveria tomar em casos de peste -, realça o caráter disciplinar das ações que visam a combater uma pandemia. Nas palavras de Foucault:

A ordem responde à peste; ela tem como função desfazer todas as confusões: a da doença que se transmite quando os corpos se misturam; a do mal que se multiplica quando o medo e a morte desfazem as proibições. Ela prescreve a cada um seu lugar, a cada um seu corpo, a cada um sua doença e sua morte, a cada um seu bem, por meio de um poder onipresente e onisciente que se subdivide ele mesmo de maneira regular e ininterrupta até a determinação

\footnotetext{
12 MUHLE, A genealogy of biopolitics: the notion of life in Canguilhem and Foucault. In: The Government of Life: Foucault, Biopolitics and Neoliberalism, 80-81, tradução nossa.

13 MUHLE, A genealogy of biopolitics: the notion of life in Canguilhem and Foucault. In: The Government of Life: Foucault, Biopolitics and Neoliberalism, 86, tradução nossa.

14 ESPOSITO, Community, immunity, biopolitics. In: Community, immunity and the proper: Roberto Esposito, 84, tradução nossa.

15 ESPOSITO, Community, immunity, biopolitics. In: Community, immunity and the proper: Roberto Esposito, 84, tradução nossa.
} 
final do indivíduo, do que o caracteriza, do que lhe pertence, do que lhe acontece ${ }^{16}$.

0 regulamento analisado por Foucault em Vigiar e Punir remete ao nosso momento. As medidas elencadas referem-se sobretudo à ordem de não sair de casa. As casas são trancadas pelo "síndico" de cada rua, que em seguida entrega todas a chaves ao "intendente de quarteirão", o qual as devolve apenas ao final da quarentena. A ampliação dos mecanismos de controle em razão da peste passa sobretudo por uma segmentação do espaço e uma incessante vigilância. Esse controle sobre o espaço, que quer em última instância impedir qualquer movimento que escape às prescrições, Foucault relaciona aos "esquemas disciplinares"17, i.e., ao modus operandi de instituições como escolas, exércitos e hospitais.

A pandemia atual, contudo, não traz à tona apenas esquemas marcadamente disciplinares, expõe também o conteúdo soberano da ação governamental. As modalidades de poder soberano, disciplinar e biopolítico, que Foucault distingue no primeiro volume de História da sexualidade, não se extinguem ao longo do tempo, antes se sobrepõem. 0 fechamento de fronteiras em decorrência do vírus denota o teor soberano da atuação estatal, uma vez que se apoia no pilar central da soberania: o controle sobre um território. 0 interesse de regular o fluxo de pessoas e mercadorias é uma questão de primeira ordem no surgimento dos primeiros burgos, quando o poder soberano se manifesta de modo inequívoco. Além das medidas que agora remetem ao poder disciplinar, como a limitação do movimento no interior das cidades, também se adotam medidas de controle estrito das fronteiras, o que alude à modalidade soberana de poder.

A racionalidade biopolítica do poder contemporâneo não atesta uma dissolução da disciplina ou da soberania, o que ocorre é uma continuidade entre essas formas de poder. 0 paradigma biopolítico manifesta-se de modo evidente na ação governamental provocada pela pandemia. Em pouco tempo se obtém os dados a respeito de qual esfera da população é mais vulnerável, bem como o índice de mortalidade relativo aos diversos intervalos de idade, possibilita-se assim que o próprio fenômeno se revele, e que o desdobramento "natural" dos eventos defina quais são os grupos de risco e quais medidas devem ser tomadas ${ }^{18}$.

Essa mesma dinâmica se explicita no tratamento da varíola, exemplo tomado por Foucault, em Segurança, Território, População, para ilustrar o modus operandi dos dispositivos de segurança. Foucault nota que o objetivo não é realizar uma demarcação entre doentes e não doentes - como ocorria no esquema disciplinar adotado para o tratamento da hanseníase -, mas sim considerar em conjunto, sem descontinuidade, doentes e não doentes. As técnicas de variolização voltam-se para a população em geral para avaliar, estatisticamente, como se comporta a doença e quais resultados se deve esperar de epidemias. Abre-se caminho para que os processos da vida manifestem o conteúdo que deve orientar a ação governamental. A filiação liberal do biopoder vincula-o a um laissez faire.

As técnicas biopolíticas, como observa Muhle, "incrementam, protegem e regulam a vida [...]; e fazem-no infiltrando os processos da vida (em vez de suprimi-los ou submetê-los) de modo a governá-los ou dominá-los a partir de seu interior"19. Para Esposito ${ }^{20}$, não há algo exterior à vida que a submeta e também não há algo que o faça a partir de seu interior. 0 caráter imunitário da biopolítica como pensado por Esposito se reflete na hipótese de Muhle

16 FOUCAULT, Vigiar e punir: nascimento da prisão, 163-164.

17 FOUCAULT, Vigiar e punir: nascimento da prisão, 164.

18 DE CONTI, Em tempos de pandemia: biopolítica, política internacional e fim da exceção humana, Le Monde Diplomatique Brasil: 17/04/2020 Disponível em: <https://diplomatique.org.br/biopolitica-politicainternacional-e-fim-da-excecao-humana/>

19 MUHLE, A genealogyof biopolitics: the notion of life in Canguilhem and Foucault. In: The Government of Life: Foucault, Biopolitics and Neoliberalism, 79, tradução nossa.

20 ESPOSITO, Imunidade(s) na era do coronavírus. Literatura italiana traduzida no Brasil: 30/04/2020 Disponível em: <https://literatura-italiana.blogspot.com/2020/04/imunidades-na-era-do-coronavirus.html> 
de que o poder mimetiza a dinâmica vital; Esposito, contudo, parece distanciar-se de Muhle em relação ao modo como isso ocorre. Onde Muhle percebe uma infiltração dos processos da vida pelo poder, Esposito identifica uma dinâmica que diz respeito à vida em comunidade.

0 conceito de immunitas que sustenta a hipótese de Esposito se manifesta em sua reflexão acerca da noção de communitas. No interior da comunidade, Esposito reconhece o funcionamento de um sistema imunitário similar ao de proteção biológica. Além de remeter à defesa do corpo humano, a noção de imunidade encontra sentido no campo jurídico, em que expressa, assim como em sua vertente biológica, uma exceção à condição normal. Como explica Esposito,

isso [exceção à condição normal] é evidente em termos legais, de acordo com os quais alguém que tem imunidade - seja parlamentar ou diplomática -, em derrogação da lei comum, não está sujeito a uma jurisdição que se aplica a todos os outros cidadãos. Mas é igualmente reconhecível nos sentidos médico e biológico do termo, segundo os quais a imunização natural ou induzida implica a habilidade do corpo de resistir, por meio de seus anticorpos, a uma infecção causada por um vírus externo ${ }^{21}$.

Em vez de ancorar sua investigação acerca da ideia de comunidade no valor semântico do prefixo latino 'cum', que alude à partilha de algo, Esposito parte do 'munus', também contido no termo 'communitas,' para lançar luz sobre o comportamento político de defesa contra ameaças, o qual coloca em prática uma dinâmica imunitária própria à vida em sociedade. A relação dialética entre 'immunitas' e 'communitas' envolve um vínculo estreito entre essas duas dinâmicas no interior da sociedade. A ideia de particularidade, de privilégio, que acompanha a noção de imunidade, relaciona-se a um esforço de sobrevivência que não anula o comum caso não exceda certos limites, para além dos quais - como uma patologia autoimune -, sacrifica o corpo que busca proteger.

Para Esposito ${ }^{22}$, um dos grandes riscos de nossa sociedade repousa na excessiva demanda por proteção, que em alguns casos tende a produzir uma impressão de perigo, real ou imaginário, com o único propósito de estabelecer mecanismos de defesa cada vez mais fortes. Como explica Esposito ${ }^{23}$, para escapar a esse artifício - para impedir que o impulso imunitário abarque todas as esferas da sociedade em seu ímpeto de apropriação do comum, de particularização, de exceção à condição ordinária -, é preciso "reencontrar um equilíbrio virtuoso entre communitas e immunitas". O corpo político é incapaz de sobreviver sem um sistema imunitário. 0 que é importante, argumenta o filósofo, é que não se ultrapasse os limites além dos quais a imunização arruína o corpo que deveria proteger. Considerando a crise que vivenciamos, ele observa que

depois de ativar, por necessidade, o princípio imunitário, [...] devemos reativar, assim que a situação o permitir, o princípio comunitário. Já a partir de agora, de resto, na crise imunitária que enfrentamos, a exigência do munus comum - do compartilhamento e da doação - é praticada. Por exemplo, por profissionais de saúde - médicos, enfermeiros, voluntários - que arriscam suas vidas para salvar outras vidas. Quando tudo isso acabar, mais esforços terão que ser feitos nesse sentido ${ }^{24}$.

\footnotetext{
${ }^{21}$ ESPOSITO, Community, immunity, biopolitics. In: Community, immunity and the proper: Roberto Esposito, 82 , tradução nossa.

22 ESPOSITO, Community, immunity, biopolitics. In: Community, immunity and the proper: Roberto Esposito, 83, tradução nossa.

23 ESPOSITO, Imunidade(s) na era do coronavírus. Literatura italiana traduzida no Brasil: 30/04/2020 Disponível em: <https://literatura-italiana.blogspot.com/2020/04/imunidades-na-era-do-coronavirus.html>

24 ESPOSITO, Imunidade(s) na era do coronavírus. Literatura italiana traduzida no Brasil: 30/04/2020 Disponível em: <https://literatura-italiana.blogspot.com/2020/04/imunidades-na-era-do-coronavirus.html>
} 
Essa passagem torna bastante evidente que a ideia de imunidade em que se baseia Esposito envolve também uma dinâmica imunitária benigna. A importância que a análise do sistema imunitário assume em sua análise leva a uma reformulação da noção de comunidade. Ao perceber a imunidade como resultado de uma exposição à alteridade, Esposito reconhece a positividade desse mecanismo, porque dele resulta a manifestação de singularidades. Como explicam Greg Bird e Jonathan Short ${ }^{25}$, o munus como exposição ao outro e à diferença expropriadora não é meramente negativo, não representa simplesmente a rejeição de algo bom; pelo contrário, o munus como exposição à diferença é em si algo positivo, porque é por meio dessa exposição que qualquer singularidade se torna possível.

Nesse sentido, o munus torna-se definidor da ideia de comunidade, não como negação da alteridade, mas antes como afirmação da singularidade, que só é possível em uma relação com o outro. Esposito distancia-se de uma concepção substancialista de comunidade, a qual se apoia na ideia expressa pelo prefixo "cum", que denota compartilhamento de algo. Para ele, a ideia de algo que se deve partilhar abre espaço para a particularização, para a apropriação do comum. A hipótese de que há algo que se compartilha abre caminho para uma rejeição de tudo aquilo que supostamente não partilha esse algo.

Uma concepção substancialista de comunidade deságua facilmente em uma configuração xenofóbica de sociedade, em uma rejeição completa da diferença. Se a apropriação do comum possibilitada por essa substancialização deriva para um comportamento excessivamente imunitário, de negação da diferença, uma comunidade pensada a partir do "munus", fundada no vazio dos espaços não submetidos a qualquer apropriação, pode ser a saída entre um sistema imunitário excessivo e a completa rejeição da negatividade representada por esse sistema. Esposito oferece-nos uma nova maneira de compreender o comum e identifica os modos de apropriação que bloqueiam sua emergência. A noção de imunidade ganha terreno no campo semântico da biopolítica e, mais que isso - ao reforçar o ponto de vista de que "não existe um poder externo à vida", bem como de que "a vida nunca se dá fora das relações de poder"26 -, constitui uma via capaz de cessar a oscilação entre uma leitura eufórica e uma leitura pessimista do conceito foucaultiano.

\section{Referências}

BIRD, G.; SHORT, J. Community, Immunity, and the Proper: An Introduction to the Political Theory of Roberto Esposito. In: BIRD, G.; SHORT, J. (Eds.). Community, Immunity and the Proper: Roberto Esposito. Oxford: Routledge, 2015.

DE CONTI, D. Em Tempos de Pandemia: biopolítica, política internacional e fim da exceção humana. Le Monde Diplomatique Brasil: 17/04/2020 Disponível em: https://diplomatique.org.br/biopolitica-politica-internacional-e-fim-da-excecao-humana/

ESPOSITO, R. Community, Immunity, Biopolitics. In: BIRD, G.; SHORT, J. (Eds.). Community, Immunity and the Proper: Roberto Esposito. Oxford: Routledge, 2015.

ESPOSITO, R. Bios: biopolítica e filosofia. Belo Horizonte: Editora UFMG, 2017.

ESPOSITO, R. Imunidade(s) na era do coronavírus. Literatura italiana traduzida no Brasil: 30/04/2020 Disponível em: https://literatura-italiana.blogspot.com/2020/04/imunidadesna-era-do-coronavirus.html

FOUCAULT, M. Em defesa da sociedade: curso no Collège de France (1975-1976). 2ª . ed. São Paulo: Editora WMF Martins Fontes, 2010.

25 BIRD; SHORT, Community, immunity and the proper: an introduction to the political theory of Roberto Esposito. In: Community, immunitt and the proper, 9.

26 ESPOSITO, Bios: biopolítica e filosofia, 60. 
8 | Vida e poder - reflexões acerca da pandemia atual

FOUCAULT, M. História da Sexualidade: a vontade de saber. 13. ed. Rio de Janeiro: Edições Graal, 1988. Volume I.

FOUCAUlT, M. Segurança, Território, População: curso dado no Collège de France (19771978). São Paulo: Martins Fontes, 2008.

FOUCAULT, M. Vigiar e Punir: nascimento da prisão. 20. ed. Rio de Janeiro: Editora Vozes, 1987.

LEMKE, T. Biopolitics: an advanced introduction. Nova Iorque: New York University Press, 2011.

LEMKE, T. Biopolitik zur Einführung. Hamburg: Junius Verlag GmbH, 2007.

LEMKE, T. Introducción a la biopolítica. Tradução de Lidia Tirado Zedillo. Ciudad de México: Fondo de Cultura Económica, 2017.

LEMKE, T. The Government of Living Beings: Michel Foucault. In: LEMKE, T. Biopolitics: an advanced introduction. Nova Iorque: New York University Press, 2011.

MUHLE, M. A Genealogy of Biopolitics: the notion of life in Canguilhem and Foucault. In: LEMM, V.; VATTER, M. (Eds.). The Government of Life: Foucault, Biopolitics and Neoliberalism. Nova Iorque: Fordham University Press, 2014. 